\title{
Crime and Punishment: Further Results *
}

\author{
Nuno GAROUPA ${ }^{\dagger}$ \\ Department d'Economia i Empresa \\ Universitat Pompeu Fabra \\ Ramon Trias Fargas 25-27 \\ 08005 Barcelona \\ Spain \\ Email: garoupa@upf.es
}

November 1998

\begin{abstract}
I consider a general specification of criminals' objective function and argue that, when the general non-expected utility theory is substituted for the traditional expected utility theory, the high-fine-lowprobability result (Becker, 1968) only holds under specific and strong restrictions.
\end{abstract}

Keywords: certainty and severity of punishment, expected and non-expected utilities.

JEL classification: D8,K4.

*I have benefited from the comments of my DPhil supervisor, Hugh Gravelle. The usual disclaimer applies.

†Phone: +34-93-5422639; Fax: +34-93-5421746 


\section{Motivation}

Becker's seminal paper on criminal behaviour dates from 1968. Becker posits that criminals are rational utility maximizers choosing in conditions of risk. His work is based on the assumption that criminals behave according to the subjective expected utility framework. Becker (1968) argued that individuals are deterred from criminal activities by a higher fine and by a higher probability of detection and conviction. The probability is costly whereas the fine is a costless transfer. Therefore, one should set the fine at its highest value. The probability of detection and conviction is used to complement the fine in deterring individuals. This result is known in the literature as the high-fine-low-probability result.

The assumption that criminals are expected utility maximizers has been at the heart of the criticism that Becker's theory has faced. ${ }^{1}$ Some empirical contradictions between expected utility predictions and actual decisions have been found. Recent findings have stressed that expected utility theory is not a good predictor in experimental situations. However that does not imply that the alternative theories perform better. ${ }^{2}$

There are already some empirical findings on criminals' behavior that are not consistent with expected utility theory. Eide (1995) makes reference to studies where criminals tend to overestimate the probability of apprehension and thus a low probability of punishment has a major deterrent effect. Block and Gerety (1995) have developed some experimental analysis on reactions to monetary penalties and risk of criminals and noncriminal students. They conclude that individuals tend to be risk averse in general but criminals tend to be more sensitive to changes in the probability of punishment than students whereas noncriminal students tend to be more sensitive to changes in the monetary penalties than criminals. ${ }^{3}$ Feeney (1986) has found that, among Californian robbers, only a small percentage had undertaken planning before committing a robbery and had thought about being caught.

The evidence seems to support the analysis of crime as a gamble (at least

\footnotetext{
${ }^{1}$ See Cook (1977), Cameron (1988), and Eide (1995).

${ }^{2}$ See Harless and Camerer (1994), Hey and Orme (1994) and Carbone and Hey (1995).

${ }^{3}$ In the expected utility framework, one may say that criminals are less risk averse than noncriminal students.
} 
for financial or property crimes). As so, it is puzzling that people who tend to be risk averse (in the sense of being insured against losses) commit crimes more frequently that one might expect.

The current economic theory has not fully responded to these criticisms: Polinsky and Shavell (1979) have discussed the importance of risk aversion in assessing Becker's theory; Lattimore and Witte (1986) have considered criminals' behavior within Kahneman and Tversky (1979) prospect theory; Eide (1995) has considered rank-dependent expected utility maximizers; Neilson and Winter (1997) and Neilson (1998) have discussed criminals' risk attitudes and state-dependent preferences. However, there has not been a more general assessment of the robustness of Becker's theory. This paper aims at filling this gap.

The paper goes as follows: in section 2, I consider a general specification of potential offender's objective function and argue that, when the general non-expected utility theory is substituted for the traditional expected utility theory, the high-fine-low-probability result only holds under specific and strong restrictions. The main conclusions are pointed out in section 3 .

\section{Main Results}

We follow an approach based on a typical utilitarian context where the social welfare is the sum of the utility of all individuals in this society. ${ }^{4}$

An individual who is not a criminal gets $y-T$ for sure. An individual who becomes a criminal has two possible incomes. If detected and convicted, he gets $y+b-f-T$; if undetected, he gets $y+b-T$. The lump-sum tax $T$ is used to finance law enforcement.

A criminal has the following utility:

$$
\Upsilon^{c}=\Upsilon(y+b-f-T, p ; y+b-T, 1-p)
$$

And if he does not commit a crime:

$$
\Upsilon^{n c}=\Upsilon(y-T, 1)
$$

\footnotetext{
${ }^{4}$ As Polinsky and Shavell (1998) argue, this utilitarian framework is of some controversy.
} 
where $\Upsilon(P)$ satisfies Machina (1995) properties. For the purpose of this note, it is enough to assume that $\Upsilon(P)$ is twice-differentiable. ${ }^{5}$

An individual commits a crime if and only if:

$$
\Upsilon^{c}(y+b-f-T, p ; y+b-T, 1-p) \geq \Upsilon^{n c}(y-T, 1)
$$

Let us define $b^{*}$ :

$$
\Upsilon^{c}\left(y+b^{*}-f-T, p ; y+b^{*}-T, 1-p\right)=\Upsilon^{n c}(y-T, 1)
$$

Since from Machina (1995) we know that $\Upsilon(P)$ satisfies first-order stochastic dominance, those individuals such that $b \geq b^{*}$ become criminals. Those individuals such that $b<b^{*}$ are deterred. The benefit $b$ is not observed by the government and is distributed according to $g(b)$ with support $[0, \infty)$.

The per-capita government's budget is given by:

$$
B=T+p f\left[1-G\left(b^{*}\right)\right]-x(p)=0
$$

where $x(p)$ is the cost of producing law enforcement, such that $x_{p}>0$ and $x_{p p}>0$.

We can now introduce the social welfare functional:

$$
\begin{aligned}
W & =\int_{0}^{b^{*}} \Upsilon^{n c}(y-T, 1) g(b) d b \\
& +\int_{b^{*}}^{\infty}\left\{\Upsilon^{c}(y+b-f-T, p ; y+b-T, 1-p)-h\right\} g(b) d b
\end{aligned}
$$

where $h$ is the harm inflicted in the community by each criminal act. ${ }^{6}$

The social planner has three policy instruments to maximize social welfare $W$ : the probability of detection and conviction $p$, the fine $f$ and the lump-sum

\footnotetext{
${ }^{5}$ In this brief note, I have followed Machina (1995). The results used in that paper are based on his 1982 Econometrica paper - in particular, Theorem I - and his 1989 Journal of Economic Theory paper. The results of the 1995 Geneva Papers on Risk and Insurance paper are less rigorous since Machina does not pay enough attention to the possibility of a kink along the certainty line (in a states of the world picture), a point which is especially important in cases of insurance. However, for the present note, they are enough.

${ }^{6}$ One can think that this crime is victimless and the harm is inflicted upon the community rather than a given individual.
} 
$\operatorname{tax} T$. When maximizing welfare, the social planner faces two constraints: $B=0$ (balanced budget) and $f \leq y-T$ (the fine is upper bounded by initial wealth minus the lump-sum tax).

The Lagrangean is $L=W+\lambda B+\mu[y-T-f]$. The first-order conditions $\operatorname{are}^{7}$ :

$$
\begin{gathered}
L_{p}=W_{p}+\lambda B_{p}=0 \\
L_{f}=W_{f}+\lambda B_{f}-\mu=0 \\
L_{T}=W_{T}+\lambda B_{T}-\mu=0 \\
L_{\lambda}=B=0 \\
L_{\mu}=y-T-f \geq 0
\end{gathered}
$$

where $\lambda$ and $\mu$ are Lagrangean multipliers. At the optimum the following expression holds:

$$
\frac{W_{f}}{W_{p}}-\frac{B_{f}}{B_{p}}=\frac{\mu}{W_{p}}
$$

The first-term is the social marginal rate of substitution between fine and probability. It measures the rate at which the social planner is just willing to substitute probability for fine. The second-term is the price ratio faced by the social planner.

When the problem admits an interior feasible solution (i.e. a less-thanmaximal fine is a feasible solution to the problem), the social marginal rate of substitution equals the price ratio. However, if for any value of the fine, the social marginal rate of substitution is always larger than the price ratio, we have a corner solution and the optimal fine must be the maximal fine.

\footnotetext{
${ }^{7}$ The second-order conditions are assumed to be satisfied. A sufficient condition is to impose that $x_{p p}$ is sufficiently positive, that is, the production technology exhibits large decreasing returns to scale.
} 
The maximal fine result holds when the rate at which the social planner is just willing to substitute probability for fine is always larger than the rate at which the social planner can change probability for fine:

$$
\frac{W_{f}}{W_{p}}>\frac{B_{f}}{B_{p}}
$$

In other words, if

$$
\frac{E\left[\Upsilon_{f}^{c}(b) \mid b \geq b^{*}\right]}{E\left[\Upsilon_{p}^{c}(b) \mid b \geq b^{*}\right]}>\frac{p\left[1-G\left(b^{*}\right)-f g(.) b_{f}^{*}\right]}{f\left[1-G\left(b^{*}\right)-p g(.) b_{p}^{*}\right]-x_{p}}
$$

for all $f$ and $p$, the optimal fine is necessarily the maximal fine.

\section{Example 1: The case of risk neutrality}

Let us start with the case of a risk-neutral expected utility maximizer where $\Upsilon^{c}=y+b-T-p f$. In this case:

$$
\begin{gathered}
\frac{W_{f}}{W_{p}}=\frac{p}{f} \\
\frac{B_{f}}{B_{p}}=\frac{p}{f}\left[1+\frac{x_{p}}{B_{p}}\right]
\end{gathered}
$$

In particular, (1) implies that:

$$
\mu=\frac{p}{f} x_{p}
$$

The rate at which the social planner is just willing to substitute probability for fine is $p / f$ which is always larger than the price ratio which is $p / f[1+$ $\left.x_{p} / B_{p}\right]$ (note that $B_{p}$ is negative). As long as the marginal cost of producing the probability is strictly positive, the optimal fine is the maximal fine. This case embodies the classical Becker's argument: the fine is a costless transfer whereas the probability is costly. Therefore, as long as the probability is costly, the optimal policy is to set the fine at its highest feasible value. 


\section{Example 2: The case of risk aversion}

Let us consider the following particular case of risk aversion: the expected utility is given by the expected income minus a risk premium $\theta(p, f)$. Therefore, we have $\Upsilon^{c}=y+b-T-p f-\theta(p, f)$. In this case:

$$
\begin{gathered}
\frac{W_{f}}{W_{p}}=\frac{p+\theta_{f}}{f+\theta_{p}} \\
\frac{B_{f}}{B_{p}}=\frac{p}{f}\left[1+\frac{x_{p}}{B_{p}}\right]+p\left[p \theta_{p}-f \theta_{f}\right] \frac{g\left(b^{*}\right)}{B_{p}}
\end{gathered}
$$

And (1) implies that:

$$
\mu=\frac{(1-G(.))\left[p \theta_{p}-f \theta_{f}\right]+x_{p}\left(p+\theta_{f}\right)}{f+\theta_{p}}
$$

Therefore, one may be able to solve (1) for $\mu=0$ : an interior solution may exist and it might be optimal. As a consequence, we can easily show that a necessary condition for a less-than-maximal fine is: $\theta_{f} / \theta_{p}>p / f$.

Note that the argument for a less-than-maximal fine complements Polinsky and Shavell (1979) case. $^{8}$ In this framework, the fine is no longer a socially costless transfer because it induces a social loss embodied by the risk premium.

\section{Example 3: The case of Yaari's dual theory}

Let us assume that individuals are risk-neutral in the context of the rank dependent expected utility theory. This is an application of Yaari's dual theory (1987).

\footnotetext{
${ }^{8}$ Polinsky and Shavell (1979) thesis is the following: let us start by considering risk neutral individuals. They compare their benefit from crime with the expected fine. The expected fine is set so that an optimal number of individuals is deterred. However, suppose that these individuals are risk-averse. Since crime is a risky activity, there is a risk premium. They compare their benefit from crime with the expected fine plus the risk premium. Therefore, to deter the same optimal number of individuals, the expected fine must be lower. In other words, the maximal fine may introduce overdeterrence.
} 
In this case, a criminal maximizes the following functional: $\Upsilon^{c}=y+b-T-$ $q(p) f$ where, following Karni and Safra (1990), there exists $\sigma \in(1 / 2,1)$ such that $q(\sigma)=\sigma, q$ is concave on $[0, \sigma)$ and $q$ is convex on $[\sigma, 1]$. Furthermore, $q_{p}$ is large in the neighborhoods of the endpoints of its domain and $q_{p p}$ is close to zero in the middle range.

In this case we can argue that $\theta=(q(p)-p) f$ and :

$$
f \theta_{f}-p \theta_{p}=\left(q(p)-q_{p} p\right) f
$$

One can check that a necessary condition for an interior solution is $q_{p} \frac{p}{q}<1$ : a one percent change of the actual probability implies a less-than-one percent change of the perceived probability.

The fine is no longer a costless transfer: there is a social loss embodied by the difference between actual and perceived expected fine. Therefore, one may have to set a less-than-maximal fine. ${ }^{9}$

\section{Conclusion}

Becker's argument is not robust when alternative specifications of behavior under uncertainty are considered. It is true that as long as preferences exhibit first-order stochastic dominance, probability and severity of punishment deter crime. However, the argument that a fine is a costless transfer does not carry through when alternative specifications are used.

In this note, I have argued that the maximal fine result only holds when the rate at which the social planner is just willing to substitute probability for fine is always larger than the rate at which the social planner can change probability for fine. For example, when individuals are risk-averse, a less-than-maximal fine may be optimal because individuals care about the expected fine and a risk premium. When individuals behave according to Yaari's dual theory, a less-than-maximal fine may be optimal because individuals care about a perceived expected fine rather than the actual expected fine.

\footnotetext{
${ }^{9} \mathrm{~A}$ similar argument is discussed by Bebchuk and Kaplow (1992) in the context of imperfect observation of the probability of detection and conviction.
} 


\section{References}

L. A. Bebchuk and L. Kaplow, 1992, Optimal sanctions when individuals are imperfectly informed about the probability of apprehension, Journal of Legal Studies, 21, 365-370.

G. S. Becker, 1968, Crime and punishment: an economic approach, Journal of Political Economy, 76, 169-217.

M. K. Block and V. E. Gerety, 1995, Some experimental evidence on differences between student and prisoner reactions to monetary penalties and risk, Journal of Legal Studies, 24, 123-138.

S. Cameron, 1988, The economics of crime deterrence: a survey of theory and evidence, Kyklos, 41, 301-323.

E. Carbone and J. D. Hey, 1995, A comparison of the estimates of expected utility and non-expected utility preference functionals, Geneva Papers on Risk and Insurance Theory, 20, 111-134.

P. J. Cook, 1977, Punishment and crime: a critique of current findings concerning the preventative effects of punishment, Law and Contemporary Problems, 5, 164-204.

E. Eide, 1995, RDEU Models of crime, University of Oslo Working Papers, WP No. C1.

F. Feeney, 1986, Robbers as decision-makers, in The reasoning criminal: rational choice perspectives on offending, edited by D. B. Cornish and R. V. Clarke. Springer-Verlang.

D. W. Harless and C. F. Camerer, 1994, The predictive utility of generalized expected utility theories, Econometrica, 62, 1251-1289.

J. D. Hey and C. Orme, 1994, Investigating generalizations of expected utility theory using experimental data, Econometrica, 62, 1291-1326.

D. Kahneman and A. Tversky, 1979, Prospect theory: an analysis in decision under uncertainty, Econometrica, 47, 263-291. 
E. Karni and Z. Safra, 1990, Rank-dependent probabilities, Economic Journal, 100, 487-495.

P. Lattimore and A. Witte, 1986, Models of decision-making under uncertainty: the criminal choice, in The reasoning criminal: rational choice perspectives on offending, edited by D. B. Cornish and R. V. Clarke. Springer-Verlang.

M. J. Machina, 1982, Expected utility analysis without the independence axiom, Econometrica, 50, 277-323.

M. J. Machina, 1989, Comparative statics and non-expected utility preferences, Journal of Economic Theory, 47, 393-405.

M. J. Machina, 1995, Non-Expected Utility and the robustness of the classical insurance paradigm, Geneva Papers on Risk and Insurance Theory, 20, 9-50.

Neilson, W. S., 1998, Optimal punishment schemes with state-dependent preferences, Economic Inquiry, 36, 266-271.

Neilson, W. S., and Winter, H., 1997, On criminals' risk attitudes, Economic Letters, 57, 97-102.

A. M. Polinsky and S. Shavell, 1979, The optimal trade-off between the probability and the magnitude of fines, American Economic Review, $69,880-891$.

A. M. Polinsky and S. Shavell, 1998, The economic theory of public law enforcement, Stanford Law School mimeo.

M. E. Yaari, 1987, The dual theory of choice under risk, Econometrica, 55, 95-115. 